\title{
PENGARUH KOMPENSASI FINANSIAL DAN KOMPENSASI NON FINANSIAL TERHADAP SEMANGAT KERJA KARYAWAN PT. BPR MITRA BALI SRISEDANA MANDIRI DI UBUD
}

\author{
I Made Wita ${ }^{1}$ \\ I Made Kartika ${ }^{2}$ \\ ${ }^{1,2}$ Fakultas Ekonomi Universitas Ngurah Rai, Denpasar
}

\begin{abstract}
ABSTRAK
Tujuan penelitian ini adalah untuk mengetahui pengaruh kompensasi finansial dan kompensasi non finansial terhadap semangat kerja karyawan pada BPR Mitra Bali Srisedana Mandiri di Ubud. Berdasarkan hasil analisis linier berganda, diperoleh bahwa $\mathrm{Y}=2,830+0,551 \mathrm{X}_{1}+0,21 \mathrm{X}_{2}$. Koefisien determinasi $\mathrm{D}=63,6 \%$, hal ini berarti bahwa besarnya kontribusi/sumbangan kompensasi finansial dan kompensasi non finansial adalah sebesar 63,6\% sedangkan sisanya sebesar $36,4 \%$ dipergunakan oleh faktor lain yang dalam penelitian ini tidak dibahas.Berdasarkan analisis uji $\mathrm{T}$ diperoleh bahwa nilai $\mathrm{T}_{1}$ hitung sama dengan 14,247 dan nilai $\mathrm{T}_{2}$ hitung sama dengan 2,566 > T tabel = 1,6 maka Ho ditolak da Ha diterima artinya kompensasi finansial dan kompensasi non finansial secara parsial berpengaruh positif dan signifikan terhadap semangat kerja karyawan pada PT. BPR Bali Srisedana Mandiri Ubud. Berdasarkan analisis uji F diperoleh bahwa $\mathrm{F}$ hitung = 110,756 lebih besar $\mathrm{F}$ tael = 3,10 maka Ho ditolak dan Ha diterima. Hal ini berarti bahwa kompensasi finansial dan kompensasi non finansial secara simultan berpengaruh positif dan signifikan terhadap semangat kerja BPR Bali Srisedana Mandiri Ubud.
\end{abstract}

Kata kunci : Kompensasi Finasial, Konpensasi Non Finansial dan Semangat Kerja

\begin{abstract}
This study have purpose was to find out the effect of financial compensation and nonfinancial compensation on employee job spirit at BPR Mitra Bali Srisedana Mandiri in Ubud. Based on the results of multiple linear analysis, it was found that $Y=2,830+0,551 X 1+0,21 X 2$. The coefficient of determination $D=63.6 \%$, this means that contribution of financial compensation and non-financial compensation is $63.6 \%$ while the remaining $36.4 \%$ by other factors which were not discussed in this study.Based on the T test analysis obtained that t 1 value is 14.287 and the t2 value is 2.566> t table $=1,6$ then Ho is rejected its means accepted that financial compensation and nonfinancial compensation partially have positive and significant effect on employee job spirit at PT. BPR Bali Srisedana Mandiri Ubud. Based on F test analysis, it is found that F count is 110.756 is greater $F$ table $=3.10$ so $\mathrm{Ho}$ is rejected and $\mathrm{Ha}$ is accepted. This means that financial compensation and non-financial compensation simultaneously have a positive and significant effect on the job spirit at BPR Bali Srisedana Mandiri Ubud.
\end{abstract}

Keywords: Financial Compensation, Non-Financial Compensation and Job Spirit 


\section{PENDAHULUAN}

Perbankan merupakan pilar terpenting dalam membangun sistem perekonomian dan keuangan Indonesia, karena perbankan memiliki peranan yang sangat penting sebagai intermediary institution (lembaga intermediasi) yaitu lembaga keuangan yang menghubungkan dana-dana yang dimiliki oleh unit ekonomi yang surplus kepada unitunit ekonomi yang membutuhkan bantuan dana (Fajri: 2013). Perkembangan perbankan di Indonesia mengalami pertumbuhan yang sangat pesat semenjak dikeluarkannya berbagai deregulasi tentang perbankan pada sekitar tahun 1980-an. Setelah dikeluarkannya UU No. 7 tahun 1992 tentang perbankan sebagaimana telah diubah dengan UU No. 10 tahun 1998 yang menyebutkan bahwa bank dibagi menjadi dua yaitu Bank Umum dan Bank Perkreditan Rakyat (BPR). BPR saat ini semakin tumbuh dan berkembang di berbagai daerah di Indonesia. Semakin berkembangnya BPR berarti semakin tersedianya kebutuhan modal bagi masyarakat golongan ekonomi lemah dan pedesaan yang diharapkan dapat meningkatkan pendapatan mereka. BPR merupakan lembaga perbankan yang mempunyai lingkup kegiatan yang lebih terbatas dibandingkan dengan Bank Umum. Agar BPR dapat berkembang dan dapat menjalankan fungsinya dengan sebaik-baiknya, BPR harus didukung oleh tenaga ahli dibidang pengelolaan.

Pertumbuhan ekonomi yang menunjukkan peningkatan merupakan angin segar bagi dunia bisnis di Indonesia, termasuk pada sektor perbankan. Kini jumlah BPR di
Indonesia mengalami peningkatan apabila dibandingkan dengan tahun sebelumnya. Selain menjadi peluang, hal tersebut merupakan alasan terjadinya peningkatan persaingan antar bank. Setiap bank berlombalomba menghimpun dana dari masyarakat dalam bentuk simpanan dan menyalurkan kembali dana tersebut berupa pinjaman. Berbagai upaya dilakukan oleh setiap pemain industri untuk mempertahankan eksistensinya. Persaingan perbankan di Indonesia menjadi lebih kompleks karena persaingannya bukan hanya persaingan antarbank, tapi persaingan juga terjadi dengan lembaga keuangan lainnya yang menawarkan produk sejenis.

Di era globalisasi abad 21 ini, persaingan bisnis antar perbankan semakin ketat. Untuk memenuhi kepuasan konsumen pada industri jasa, kualitas pelayanan sangat penting bagi perusahaan untuk dikelola dengan baik. Karena yang dibutuhkan oleh masyarakat (nasabah) adalah kepuasan dalam hal pelayanan oleh pihak bank. Konsumen akan sulit di puaskan karena telah terjadi pergeseran, yang semula hanya untuk memenuhi kebutuhan menigkat menjadi harapan (expectation) untuk memenuhi kepuasan. Umumnya nasabah yang tidak puas akan menyampaikan pengalaman buruknya kepada orang lain dan bisa di bayangkan betapa besarnya kerugian dari kegagalan memuaskan nasabah. Nasabah sebagai objek yang harus di puaskan mempunyai harapan yang abstrak, sehingga melahirkan persepsi yang berbeda-beda tentang bagaimana pelayanan yang baik dari bank untuk diberikan kepada nasabah. 


\begin{abstract}
Sumber Daya Manusia (SDM) merupakan elemen yang sangat penting di dalam suatu perusahaan dibandingkan dengan elemen lain seperti modal, teknologi, dan uang, sebab manusia itu sendiri mengendalikan elemen-elemen yang lain. Manusia memilih teknologi, manusia yang mencari uang, manusia yang menggunakan dan memeliharanya. Dengan perkataan lain,manusia merupakan kekayaan (asset) yang paling utama dan sangat strategis yang dimiliki oleh suatu perusahaan. Oleh sebab itu, pengelolaan sumber daya manusia dalam suatu perusahaan menjadi suatu hal yang sangat penting dalam usaha meningkatkan efektivitas dan efisiensi produktivitas suatu perusahaan. Dengan demikian sudah selayaknya karyawan diperlakukan secara layak dan adil sesuai dengan apa yang telah diberikannya kepada perusahaan,yang dapat berimplikasi kepada timbulnya semangat kerja.

Sebagaimana diketahui, suatu perusahaan dibentuk untuk mencapai tujuan bersama baik perusahaan yang bergerak di bidang manufaktur maupun jasa. Untuk mencapai tujuan yang telah ditentukan, maka diperlukan semangat kerja yang mampu memberikan dorongan tersendiri baik dalam hal meningkatkan produksi dan produktivitas kerja karyawan.
\end{abstract} Menurut Nitisemito, (2000:96) menyatakan bahwa semangat kerja adalah melakukan pekerjaan lebih giat dengan jalan memperkecil kekeliruan-kekeliruan dalam pekerjaan, mempertebal rasa tanggung jawab, serta dapat menyelesaikan tugas tepat pada waktunya sesuai dengan rencana yang diharapkan. Sedangkan, menurut Gellerman (Ahmad Tohardi, 2002:428) menyatakan bahwa semangat kerja adalah istilah yang menyangkut keperluan diluar pekerjaan seperti pendapatan, rasa aman dan kedudukannya yang lebih tinggi dalam masyarakat, keputusan terhadap pekerjaan misalnya minat kerja, peluang untuk maju dan prestise di dalam perusahaan, kepuasan pribadi dan rasa bangga atas profesinya. Namun, semangat kerja karyawan memiliki beberapa indikator yang mempengaruhinya sehingga semangat kerja dapat meningkat dan menurun.

Salah satu indikator yang mempengaruhi semangat kerja adalah pemberian imbalan atau balas jasa. Secara umum, karyawan bekerja karena ingin memperoleh imbalan atau balas jasa dari perusahaan untuk memenuhi kebutuhan hidupnya. Ada tiga kategori kebutuhan individu yaitu eksistensi, keterhubungan, dan pertumbuhan (Rivai, 2006:462). Masalah karyawan tidak lepas dari hak mereka untuk memperoleh kesempatan kerja dengan gaji yang memadai dan kehidupan yang layak. Semakin tinggi gaji yang diterima oleh karyawan akan dapat meningkatkan semangat kerjanya. Untuk meningkatkan semangat kerja karyawan, pimpinan perusahaan harus mampu memotivasi mereka. Motivasi menyangkut beberapa hal dan salah satunya adalah dengan pemberian kompensasi finansial. Menurut Hasibuan (2001:200) menyatakan bahwa insentif adalah daya perangsang yang diberikan kepada karyawan tertentu berdasarkan prestasi kerjanya, agar karyawannya

terdorong 
meningkatkan produktivitas kerjanya. Pemberian insentif dari masingmasing perusahaan berbeda-beda baik ditinjau dari segi jumlah, cara dan komponennya baik kompensasi berupa finansial maupun non finansial. Menurut Sirait (2006:33) Kompensasi finansial merupakan semua dorongan yang dapat dinilai dengan uang yang bukan saja meliputi gaji yang pantas tetapi bonus, komisi, dan tunjangan yang diberikan berupa uang. Sedangkan, kompensasi non finansial merupakan semua dorongan yang berupa penghargaan, hiburan, terjaminnya tempat kerja dan terjaminnya komunikasi yang baik antara atasan dan bawahan.

\section{Kompensasi}

finansial

merupakan salah satu aspek yang paling sensitif di dalam hubungan kerja. Kompensasi finansial adalah sesuatu yang diterima pegawai sebagai penukar atas kontribusi jasa mereka bagi organisasi Werther dan Davis dalam (Sinambela, 2016 : 218). Kompensasi finansial adalah semua balas jasa yang diterima seorang karyawan dari perusahaannya sebagai akibat dari jasa atau tenaga yang telah diberikannya pada perusahaan tersebut Singodimedjo dalam (Edy Sutrisno, 2015 :182).

Kompensasi

finansial merupakan salah satu aspek yang paling sensitif didalam hubungan kerja. Kompensasi finansial dipandang sebagai hak dan merupakan sumber pendapatan utama, karena itu jumlahnya harus memenuhi kebutuhan untuk dirinya dan keluarganya, serta adanya jaminan kepastiaan penerimaannya. Kompensasi tidak hanya diberikan dalam bentuk uang, tetapi dapat juga berbentuk materiil atau benda.
Disamping uang dan materiil, kompensasi finansial dapat pula diberikan perusahaan berupa fasiltas atau kemudahan- kemudahan bagi para karyawannya.

Sedangkan untuk finansial non insentif, pihak manajemen memberikan penghargaan pengabdian setelah karyawan bekerja selama lima tahun serta sepuluh tahun, penghargaan yang diberikan berupa karyawan terbaik setiap tiga bulan sekali dan promosi. Namun, salah satu yang belum dipenuhi pihak manajemen untuk finansial non insentif adalah rekreasi untuk karyawan. Karyawan di PT. BPR Mitra Bali Srisedana Mandiri di Ubud melakukan rekreasi berupa tirta yatra dengan menggunakan uang suka duka yang dikumpulkan dari uang keanggotaan suka duka yang setiap bulannya dikurangi dari kompensasi yang diterima. Hal tersebut juga akan mempengaruhi turunnya semangat kerja karena adanya kejenuhan dalam melakukan tugas dan tanggung jawabnya dalam bekerja.

Berdasarkan hal-hal yang telah diuraikan di atas maka peneliti sangat tertarik untuk melakukan penelitian yang berjudul "Pengaruh Kompensasi Finansial dan Kompnesasi Non Finansial Terhadap Semangat Kerja Karyawan di PT. BPR Mitra Bali Srisedana Mandiri di Ubud".

\section{METODE PENELITIAN}

Penelitian ini dilakukan Penelitian ini dilakukan PT. BPR Bali Srisedana Mandiri di Ubud. Obyek penelitian ini adalah kompensasi finansial dan kompensasi non finansial serta semangat kerja 
karyawan. Penelitian pada PT. BPR Bali Srisedana menggunakan 2 (dua) variabel bebas dan 1 (satu) variabel terikat yaitu: variabel terikat yaitu suatu variabel yang memiliki ketergantungan antara variabel yang satu dengan yang lain, sedangkan dalam penelitian ini variabel terikatnya adalah semangat kerja karyawan (Y). Variabel bebas, yaitu variabel yang tidak mempunyai ketergantungan. Dalam penelitian ini yang termasuk kedalam variabel bebas adalah kompensasi finansial $\left(\mathrm{X}_{1}\right)$, dan kompensasi non finansial $\left(\mathrm{X}_{2}\right)$. Jenis data yang diperlukan dalam penelitian ini adalah data kuantitatif dan data kualitatif. Sumber data yang digunakan dalam penelitian ini adalah data primer dan data sekunder. Responden responden dalam penelitian ini adalah semua jumlah karyawan digunakan sebagai sampel sehingga jumlah sampel dalam penelitian ini sebanyak 130 orang. Teknik pengambilan sampel yang digunakan dalam penelitian ini adalah penelitian sensus.

Analisis data yang digunakan untuk mengetahui pengaruh

\section{HASIL DAN PENELITIAN}

Untuk menganalisis pengaruh kompensasi finansial dan kompensasi non finansial terhadap semangat kerja karyawan pada PT. BPR Mitra Bali Srisedana Mandiri Ubud. Dengan kompensasi finansial dan kompensasi non finansial terhadap semangat kinerja karyawan dalam penelitian ini menggunakan bantuan Statistical Package for the Social Sciences (SPSS) Version 21.00 For Windows., dengan langkah-langkah analisis menggunakan analisis regresi linier berganda, koefisien determinasi $\left(\mathrm{R}^{2}\right)$, analisis uji t (uji parsial) dan analisis uji F (uji simultan).

Untuk mengetahui besarnya sumbangan kompensasi finansial dan kompensasi non finansial terhadap semangat kerja karyawan, yang dinyatakan dengan presentase. Berdasarkan hasil analisis SPSS version 23.0 for windows pada table 5.3 diatas diperoleh besarnya $\mathrm{R}^{2}=$ 0,036 maka besarnya koefisien determinasi ( $\mathrm{D}=63,36 \%)$. Hal ini berarti bahwa besarnya sumbangan kompensasi finansial dan kompensasi non finansial terhadap semangat kerja karyawan adalah sbesar $63,6 \%$. Sedangkan sisanya sebesar $36,4 \%$ dipengaruhi oleh faktor lain yang dalam penelitian ini tidak dibahas.

menggunakan analisis regresi linier berganda dengan bantuan komputer program SPSS version 23 for windows, sebagai berikut: 
Tabel 1

Rangkuman Hasil Penelitian SPSS Version 23.0 for Windows. Pengaruh Kompensasi Finansial dan Kompensasi Non Finansial Terhadap Semangat Kerja Karyawan pada PT. BPR Mitra Bali Srisedana Mandiri Ubud tahun 2018

\begin{tabular}{|c|c|c|c|}
\hline Variabel & Koefisien Regresi & t hitung & Signifikan $\mathrm{t}$ \\
\hline (1) & $(2)$ & (3) & (4) \\
\hline Constanta & 2,830 & 2,888 & 0,005 \\
\hline Kompensasi Finansial & 0,551 & 14,247 & 0,000 \\
\hline Kompensasi & 0,200 & 5,566 & 0,000 \\
\hline \multicolumn{4}{|l|}{ Finansial } \\
\hline $\mathrm{R}$ & $=0,797$ & & \\
\hline $\mathrm{R}^{2}$ & $=0,636$ & & \\
\hline F hitung & $=110,75$ & & \\
\hline Sig F hitung & $=0,000$ & & \\
\hline
\end{tabular}

Sumber : data diolah Tahun 2018

Analisis ini digunakan untuk mengetahui besarnya kompensasi finansial dan kompensasi non finansial terhadap semangat kerja karyawan sebagai berikut :

$\mathrm{Y}=\mathrm{a}+\mathrm{b} 1 \mathrm{x} 1+\mathrm{b} 2 \mathrm{x} 2$, berdasarkan hasil analisis SPSS 23.0 version for windows, pada table 5.3 diperoleh besar nilai a (constanta) sebesar $\mathrm{a}=2,830$, b1 (koefisien regresi X1) sebesar 0,551 dan b2 (koefisien regresi X2) sebesar 0,200. Berdasarkan nilai tersebut maka persamaan regresi linier berganda adalah $\mathrm{y}=2,850+0,551 \mathrm{X} 1+0,200$ $\mathrm{X} 2$ hal ini memberikan iformasi sebagai berikut :

1. Nilai a $=2,830$, artinya apabila tidak ada perhatian terhadap kompensasi finansial dan kompensasi non finansial (constanta) maka skor semangat kerja karyawan adalah sebesar rata-rata 2,830.

2. Nilai $b 1=0,551$, artinya apabila skor kompensasi finansial meningkat sebesar 1 satuan, maka semangat kerja karyawan mengalami peningkatan sebesar 0,551 denagn asumsi skor kompensasi non finansial konstan.

Nilai b2 $=0,200$, artinya apabila skor kompensasi non finansial meningkat sebesar 1 satuan, maka skor semangat kerja karyawan akan meningkat sebesar 0,200 dengan asumsi skor kompensasi finansial konstan.

\section{Analisis Determinasi}

Untuk mengetahui besarnya sumbangan kompensasi finansial dan kompensasi non finansial terhadap semangat kerja karyawan, yang dinyatakan dengan presentase. Berdasarkan hasil analisis SPSS version 23.0 for windows pada table 5.3 diatas diperoleh besarnya $\mathrm{R}^{2}=$ 0,036 maka besarnya koefisien determinasi $(\mathrm{D}=63,36 \%)$. Hal ini berarti bahwa besarnya sumbangan kompensasi finansial dan kompensasi non finansial terhadap semangat kerja karyawan adalah sbesar $63,6 \%$. Sedangkan sisanya sebesar $36,4 \%$ 
dipengaruhi oleh faktor lain yang dalam penelitian ini tidak dibahas.

\section{Uji T-test}

\section{Pengaruh kompensasi finansial terhadap semangat kerja karyawan}

Berdasarkan hasil analisis gambar 5.1 di atas bahwa nilai $t_{1}$ hitung diperoleh sebesar 14,247 > dari t tabel sebesar 1,658 maka Ho ditolak dan $\mathrm{H}_{1}$ diterima. Hal ini berarti bahwa kompensasi finansial mempunyai pengaruh posotif dan signifikan terhadap semangat kerja karyawan pada PT. BPR Mitra Bali Srisedana Mandiri Ubud.

2. Pengaruh kompensasi non finansial berpengaruh terhadap semangat kerja karyawan adalah pengaruh yang positif dan signifikan atau diperoleh secara kebetulan saja.

Berdasarkan hasil analisis 5.2 diatas menunjukkan bahwa nilai t2 hitung diperoleh sebesar 5,566 > nilai $\mathrm{t}$ tabel $=1,658$ maka Ho ditolak dan Hi diterima. Hal ini berarti bahwa kompensasi non finansial bepengaruh positif dan signifikan terhadap semangat kerja karyawan pada PT. BPR Mitra Bali Srisedana Mandiri Ubud.

\section{Uji F (F-test)}

Untuk menguji nyata-tidaknya pengaruh variabel bebas kompensasi finansial $\left(\mathrm{X}_{1}\right)$, dan kompensasi non finansial $\left(\mathrm{X}_{2}\right)$ secara simultan terhadap variabel terikat semangat kerja karyawan (Y), maka dilakukan uji signifikasi dengan uji $\mathrm{F}$ hitung $=$ $110,75>\mathrm{F}$ tabel $=3,07$ maka Ho ditolak dan Ha diterima. Oleh karena nilai $\mathrm{F}$ hitung berada pada daerah penolakan Ho, hal ini berarti bahwa kompensasi finansial dan kompensasi non finansial berpegaruh positif dan signifikan terhadap semangat kerja karyawan PT. BPR Mitra Bali Srisedana Mandiri Ubud.

Jadi dapat disimpulkan bahwa sesuai dengan hipotesis yang dibuat yang bunyinya : diduga kompensasi finansial dan kompensasi non finansial berpengaruh positif dan signifikan secara simultan terhadap semangat kerja karyawan. Artinya bahwa semakin besar kompensasi finansial dan kompensasi non finansial yang diberikan secara simultan atau secara bersama-sama maka semangat kerja karyawan pada PT. BPR Mitra Bali Srisedana Mandiri Ubud akan semakin meningkat pula (hipotesis terbukti).

\section{Simpulan}

1. Kompensasi finansial dan kompensasi non finansial berpengaruh positif dan signifikan secara parsial terhadap semangat kerja karyawan pada PT. BPR Mitra Bali Srisedana Mandiri Ubud. Hal ini ditunjukkan oleh nilai $\mathrm{t}_{1}$ hitung $=14,247$ dan nilai $\mathrm{t}_{2}$ hitung $=5,566>\mathrm{t}$ tabel $=1,658$.

2. Kompensasi finansial dan kompensasi non finansial berpengaruh positif dan signifikan secara simultan terhadap semangat kerja karyawan pada PT. BPR Mitra Bali Srisedana Mandiri Ubud. Hal ini ditunjukkan oleh nilai $\mathrm{f}$ hitung $=110,75>\mathrm{t}$ tabel $=3,07$. 
Saran

1. Kepada pihak perusahaan bagi karyawan yang berprestasi diberikan reward secara insidental sehingga karyawan yang lainnya juga termotivasi untuk bekerja yang lebih giat lagi.

2. Kepada karyawan semangat kerjanya yang sudah bagus hendaknya dipertahankan dan bila perlu ditingkatkan lagi.

\section{REFERENSI}

Ahmad Tohardi. 2012. Pemahaman Praktis Manajemen Sumber Daya Manusia, Universitas Tanjung Pura, Mandar Maju, Bandung.

Anwar Prabu Mangkunegara, 2013, Manajemen Sumber Daya Manusia PT. Remaja Posta Karya, Bandung.

Ardana, I Komang, dkk, 2012, Manajemen Sumber daya Manusia, Cetakan Pertama, Graha Ilmu, Yogyakarata

Davis, Keith. 2015. Perilaku Organisasi.

Jilid 1.Terjemahan Agus Dharma. Jakarta:Erlangga.

Edy Sutrisno,2014. Manajemen Sumber Daya Manusia, Kencana Pranada Media Grup Jakarta.

Flippo, Edwin B, 1991. Manajemen Personalia, Terjemahan Moh Masud. Jilid 1 dan 2 Edisi 6. Jakarta Erlangga.

Garry Dessler, 2014, Human Behavior: Improvind Performance at Work Virginia : Reston Publising Company, Inc.

Ghozali, Imam, 2011. Aplikasi Analisis Multivariate Dengan
Program IBM SPSS 19 (edisi kelima). Semarang Universitas Diponegoro.

Gorda I.G.H, 2005. Manajemen Sumber Daya Manusia. Penerbit Astabrata. Denpasar.

Husein Umar dan Purnomo Setiadi Akbar, 2015, Pengantar Statistika, Penerbit : Bumi Aksara, Jakarta.

M.Yani, 2012, Manajemen Sumber Daya Manusia, Mitra Wacana Media.

Malayu SP. Hasibuan, 2012, Manajemen Sumber Daya Manusia, Edisi Relisi, Bumi Angkasa, Jakarta.

Mulyadi, 2015, Manajemen Sumber Daya manusia, Penerbit IN MEDIA

Sedarmayanti, 2011, Manajemen Sumber Daya manusia, Penerbit : PT.Refika Aditama, Bandung.

Singodimedjo, Markum. 2014, Manajemen Sumber Daya Manusia, Surabaya : SMMAS

Sugiyono, 2014, Metode Penelitian Kuantitatif, Kualitatif dan $R \& D, \quad$ Penerbit Alfabeta Bandung.

Suwatno dan Donni Juni Priansa. 2011, Manajemen Sumber Daya Manusia dalam Organisasi Publik dan Bisnis, Bandung : Alfabeta.

Syofian Siregar, 2014, Metode Penelitian Kuantitatif dilengkapi dengan Perbandingan Perhitungan Manual \& SPSS, Cetakan Kedua, Penerbit : Kencana Premedya Group, Jakarta. 